\title{
Investigating product development strategy in beverage industry using factor analysis
}

\author{
Naser Azad, Seyed Mohsen Seyed Aliakbar, Seyed Foad Zarifi and Somayeh Hozouri*
}

Department of Management, Islamic Azad University, South Tehran Branch, Tehran, Iran

\section{H R O N I LE AB S TRACT}

Article history:

Received October 1, 2012

Received in revised format

22 January 2013

Accepted 23 January 2013

Available online

January 262013

Keywords:

Factor analysis

Product development

Market share adjustment
Selecting a product development strategy that is associated with the company's current service or product innovation, based on customers' needs and changing environment, plays an important role in increasing demand, increasing market share, increasing sales and profits. Therefore, it is important to extract effective variables associated with product development to improve performance measurement of firms. This paper investigates important factors influencing product development strategies using factor analysis. The proposed model of this paper investigates 36 factors and, using factor analysis, we extract six most influential factors including information sharing, intelligence information, exposure strategy, differentiation, research and development strategy and market survey.

The first strategy, partnership, includes five sub-factor including product development partnership, partnership with foreign firms, customers' perception from competitors' products, Customer involvement in product development, inter-agency coordination, customer-oriented approach to innovation and transmission of product development change where inter-agency coordination has been considered the most important factor. Internal strengths are the most influential factors impacting the second strategy, intelligence information. The third factor, introducing strategy, introducing strategy, includes four sub criteria and consumer buying behavior is the most influencing factor. Differentiation is the next important factor with five components where knowledge and expertise in product innovation is the most important one. Research and development strategy with four sub-criteria where reducing product development cycle plays the most influential factor and finally, market survey strategy is the last important factor with three factors and finding new market plays the most important role.

\section{Introduction}

Selecting a product development strategy that is associated with the company's current service or product innovation, based on customers' needs and changing environment, plays important role in increasing demand, increasing market share, increasing sales and profits. Therefore, it is important to extract effective variables associated with product development to improve performance measurement

*Corresponding author.

E-mail addresses: dr.naserazad@yahoo.com (N. Azad) 
of firms. Prašnikar and Škerlj (2006) investigated the organizational and managerial factors lying behind time-to-market in four firms in Central and Eastern Europe. They presented some factors incorporated into a diagnostic framework of new product development in generic pharmaceutical companies. Sun and Wing (2005) did an investigation to find critical success factors for new product development in the Hong Kong toy industry. González and Palacios (2002) investigated the effect of new product development techniques on new product success in Spanish firms. They suggested that only a subset of popular methods is substantially associated with new product success in Spanish companies. The study also identified the main contributors to new product development (NPD) effectiveness in Spanish firms.

Langerak and Hultink (2008) investigated the effects of new product development acceleration method on development speed from 233 manufacturing firms. They reported that 5 approaches including supplier involvement, lead user involvement, speeding up activities and tasks, training and rewarding of employees, and simplification of organizational structure could increase development speed, whereas 2 approaches including implementing support systems and techniques and stimulating inter-functional coordination could decrease development speed. In their study, there were two approaches of reduction of parts and components and emphasizing the customer, which had no impact on development speed. The results further demonstrated that firms developing various kinds of new products should implement various NPD acceleration approaches, as the speed impact of six out of nine approaches was dependent on the degree of product innovativeness.

Lee and Wang (2012) investigated the performance effect of new product development processes for distinct scenarios under various supplier-manufacturer relationships. They identified four kinds of supplier-manufacturer relationships, namely sequential mode, passive supplier involvement, active supplier involvement, and strategic development. They justified the NPD performances of these supplier-manufacturer relationship configurations under workload impacts and provided managerial insights.

Lu and Yang (2004) extended the idea of NPD process approach to a new environmental context, Taiwan's information technology industry, and a new business kind, original design manufacturing, ODM. They found that the higher the perceived importance of R\&D-marketing cooperation is, the higher the attained level of R\&D-marketing cooperation will be. Akgün et al. (2007) examined the impact of team stressors, consisting of team crisis and anxiety, on the project/process outcomes, such as team learning, speed-to-market, etc. They reported that when a high degree of management support was observed during the project, team crisis positively impacted team learning, speed-to-market and new product success, and team anxiety positively influenced speed-to-market. They also found that team anxiety impacted the proficiency in the product development stage regardless of low or high level of management support.

The proposed study of this paper uses factor analysis to investigate the most influential factors on beverage industry for product development. Factor analysis has been successfully used to detect important factors in different studies (Karimi et al., 2012). Azad et al. (2012a) presented an empirical study to learn more about challenges in carpet industry using factor analysis. Azad et al. (2012b) presented a study to find important factors impacting marketing strategies based on factor analysis. The study designed and distributed a questionnaire consists of 64 questions. The proposed study used Skewness analysis to reduce the factors into 44 items and reports 8 important factors including business environment, communication chain technology, good organizational relationship, leadership cost strategy, performance risk, ecommerce strategy, encouraging strategy and consistency in organizational performance. Azad and Esmaeili (2012c) performed a survey on measuring the effect of website on customer satisfaction. 
The organization of this paper first presents details of the survey in section 2 while section 3 presents the results and finally concluding remarks are given in the last to summarize the contribution of the paper.

\section{The proposed study}

The purpose of this paper is to develop some strategies for market share adjustment in a beverage firm in Iran called Behnoosh. The proposed study designs a questionnaire and distributes it among 263 experts. Cronbach alpha is calculated as $89 \%$, which well above the minimum desirable limit of 0.70 . There are 36 variables and using factor analysis, we extract six factors where Kaiser-MeyerOlkin Measure of Sampling Adequacy was 77.5\% (Chi-Square=4523 df=630 Sig.=0.000), which also confirms the results of our survey.

\section{The results}

The results of the implementation of factor analysis have provided six factors, which are explained next.

\subsection{Partnership strategy}

Partnership strategy includes six options including Product development partnership, Partnership with foreign firms, Customers' perception from competitors' products, Customer involvement in product development, Inter-agency coordination, Customer-oriented approach to innovation and Transmission of product development change. Table 1 shows the weights for all factors and the results indicate that Inter-agency coordination is the most important items in this part of our survey.

\section{Table 1}

The summary of factor analysis for partnership strategy

\begin{tabular}{lcccc}
\hline Option & Factor weight & Eigenvalues & \% of variance & Accumulated \\
\hline Product development partnership & .636 & & & \\
Partnership with foreign firms & .434 & & & \\
Customers' perception from competitors' products & .709 & & & \\
Customer involvement in product development & .646 & & \\
Inter-agency coordination & .716 & 2.990 & \\
Customer-oriented approach to innovation & .707 & & \\
Transmission of product development change & .681 & & \\
\hline
\end{tabular}

\subsection{Intelligence information}

Intelligence information includes implementing product development processes, internal strengths, knowledge and expertise in product innovation, the level of information and communication technology, using market research. Table 3 demonstrates the results of our survey.

Table 2

The summary of factor analysis for intelligence information

\begin{tabular}{lcccc}
\hline Option & Factor weight & Eigenvalues & \% of variance & Accumulated \\
\hline Implementing product development processes & .781 & & & $\mathbf{5 1 . 2 4 1}$ \\
Internal strengths & $\mathbf{. 8 0 7}$ & $\mathbf{2 . 5 6 2}$ & $\mathbf{5 1 . 2 4 1}$ & \\
Knowledge and expertise in product innovation & .634 & & & \\
The level of information and communication & .668 & & \\
technology & .672 & & & \\
Using market research & & & \\
\hline
\end{tabular}




\subsection{Introducing strategy}

Product development strategy includes four variables of different selling scenarios, branding, consumer buying behavior, market environment created by the company.

Table 3

The summary of factor analysis for introducing strategies

\begin{tabular}{lcccc}
\hline Option & Factor weight & Eigenvalues & \% of variance & Accumulated \\
\hline Selling scenarios & 0.709 & & & \\
Branding & 0.710 & & & \\
Consumer buying behavior & $\mathbf{0 . 7 8 2}$ & $\mathbf{1 . 9 9 4}$ & $\mathbf{4 9 . 8 3 9}$ & $\mathbf{4 9 . 8 3 9}$ \\
Market environment & 0.612 & & & \\
\hline
\end{tabular}

\subsection{Differentiation strategy}

This strategy includes Create a competitive advantage, corporate reputation, flexibility in product design and development, technology changes, application sales' triggers strategies. Table 4 shows the results of our survey.

\section{Table 4}

The summary of factor analysis for differentiation strategy

\begin{tabular}{lcccc}
\hline Option & Factor weight & Eigenvalues & \% of variance & Accumulated \\
\hline Implementing product development processes & .706 & & & \\
Internal strengths & .649 & & $\mathbf{4 5 . 7 7 7}$ & $\mathbf{4 5 . 7 7 7}$ \\
Knowledge and expertise in product innovation & $\mathbf{. 7 6 4}$ & $\mathbf{2 . 2 8 9}$ & $\mathbf{4 5 9}$ \\
The level of information and communication & .673 & & \\
technology & .577 & & \\
\hline Using market research & & & \\
\hline
\end{tabular}

\subsection{Research \& development strategy}

This strategy includes Sales management, increase in product development requirements, reducing product development cycle and reducing delivery of products. Table 5 shows the results of our survey.

Table 5

The summary of factor analysis for research and development strategy

\begin{tabular}{lcccc}
\hline Option & Factor weight & Eigenvalues & \% of variance & Accumulated \\
\hline Sales management & .668 & & & \\
Increase in product development requirements & .607 & & & \\
Reducing product development cycle & $\mathbf{. 8 3 2}$ & $\mathbf{1 . 9 3 6}$ & $\mathbf{4 8 . 3 9 8}$ & $\mathbf{4 8 . 3 9 8}$ \\
Reducing delivery of products & .656 & & & \\
\hline
\end{tabular}

\subsection{Market survey strategy}

Finally, the last strategy includes sales management, increase in product development requirements, reducing product development cycle and reducing delivery of products. Table 6 shows the results of our survey.

\section{Table 6}

The summary of factor analysis for market survey strategy

\begin{tabular}{lcccc}
\hline Option & Factor weight & Eigenvalues & \% of variance & Accumulated \\
\hline Customers' goals and requirements & .738 & & & \\
Taking advantage of new technology achievements & .805 & & & \\
Finding new market & $\mathbf{. 7 0 7}$ & $\mathbf{1 . 6 9 2}$ & $\mathbf{5 6 . 3 8 7}$ & $\mathbf{5 6 . 3 8 7}$ \\
\hline
\end{tabular}




\section{Conclusion}

In this paper, we have performed different strategies associated with product development in beverage industry in Iran. The proposed study determined six important factors influencing product development including partnership, intelligence information, introducing strategy, differentiating strategy, research and development and market survey strategies. The first strategy, partnership, includes five sub-factor including product development partnership, partnership with foreign firms, customers' perception from competitors' products, Customer involvement in product development, inter-agency coordination, customer-oriented approach to innovation and transmission of product development change where inter-agency coordination has been considered the most important factor.

Internal strengths are the most influential factors impacting the second strategy, intelligence information. The third factor, introducing strategy, introducing strategy, includes four sub criteria and consumer buying behavior is the most influencing factor. Differentiation is the next important factor with five components where knowledge and expertise in product innovation is the most important one. Research and development strategy with four sub-criteria where reducing product development cycle plays the most influential factor and finally, market survey strategy is the last important factor with three factors and finding new market plays the most important role.

\section{Acknowledgement}

The authors would like to thank the anonymous referees for constructive comments on earlier version of this paper.

\section{References}

Akgün, A.E., Byrne, J.C., Lynn, G.S., \& Keskin, H. (2007). Team stressors, management support, and project and process outcomes in new product development projects. Technovation, 27(10), 628-639.

Azad, N., Seyed Aliakbar, S.M., \& Ansari, M. (2012a). Investigating knowledge management critical success factors in carpet industry. Management Science Letters, 2(8), 2717-2722.

Azad, N., Seyed Aliakbar, S.M., \& Nayeri, A. (2012b). Critical success factors in industrial marketing supply chain management. Management Science Letters, 2(7), 2667-2672.

Azad, N., \& Esmaeili, A. (2012c). A survey on measuring the effect of website on customer satisfaction. Management Science Letters, 2(5), 1639-1644.

González, F.J.M., \& Palacios, T.M.B. (2002). The effect of new product development techniques on new product success in Spanish firms. Industrial Marketing Management, 31(3), 261-271.

Karimi, P., Kloshani, M., \& Bakhshizadeh, A. (2012). A comparative study on emotional intelligence and cognitive between successful and unsuccessful entrepreneurs. Management Science Letters, 2(6), 2071-2076.

Langerak, F., \& Hultink, E.J. (2008). The effect of new product development acceleration approaches on development speed: A case study. Journal of Engineering and Technology Management, 25(3), 157-167.

Lee, Y.H., \& Wang, K.J. (2012). Performance impact of new product development processes for distinct scenarios under different supplier-manufacturer relationships. Mathematics and Computers in Simulation, 82(11), 2096-2108.

Lu, L.Y.Y., \& Yang, C. (2004). The R\&D and marketing cooperation across new product development stages: An empirical study of Taiwan's IT industry. Industrial Marketing Management, 33(7), 593-605

Prašnikar, J., \& Škerlj, T. (2006). New product development process and time-to-market in the generic pharmaceutical industry. Industrial Marketing Management, 35(6), 690-702. 
Sun, H., \& Wing, W.C. (2005). Critical success factors for new product development in the Hong Kong toy industry. Technovation, 25(3), 293-303 